\title{
Visual $\mathrm{H}_{2}$ sensor for monitoring biodegradation of
}

\section{magnesium implants in vivo}

\author{
Daoli Zhao ${ }^{\mathrm{a}}$, Tingting Wang ${ }^{\mathrm{a}}$, William Hoagland ${ }^{\mathrm{b}}$, David Benson ${ }^{\mathrm{b}}$, Zhongyun Dong ${ }^{\mathrm{c}}$, Shuna \\ Chen ${ }^{\mathrm{c}}$, Da-Tren Chou ${ }^{\mathrm{d}}$, Daeho Hong ${ }^{\mathrm{d}}$, Jingyao Wu ${ }^{\mathrm{d}}$, Prashant N. Kumta ${ }^{\mathrm{d}, \mathrm{e}, \mathrm{f}}$ and William R. \\ Heineman $^{\mathrm{a}, *}$ \\ ${ }^{a}$ Department of Chemistry, University of Cincinnati, Cincinnati, Ohio 45221, USA \\ ${ }^{\mathrm{b}}$ Element One, Inc. Boulder, CO, 80301, USA \\ ${ }^{c}$ Department of Internal Medicine, University of Cincinnati, Cincinnati, Ohio 45267, USA \\ ${ }^{d}$ Department of Bioengineering, University of Pittsburgh, Pittsburgh, PA, 15261, USA \\ ${ }^{e}$ Department of Chemical and Petroleum Engineering, University of Pittsburgh, Pittsburgh, PA, \\ 15261, USA \\ ${ }^{f}$ Department of Mechanical Engineering and Materials Science, University of Pittsburgh, \\ Pittsburgh, PA 15261, USA \\ * Corresponding author: Tel.: +1-513-556-9210; fax: +1-513-556-9329 \\ E-mail address: William.Heineman@uc.edu
}

\begin{abstract}
A visual sensor for $\mathrm{H}_{2}$ was used to transdermally monitor $\mathrm{H}_{2}$ that originated from biodegrading magnesium (Mg) alloys implanted subcutaneously in mice. The visual sensor consisted of a thin film of $\mathrm{H}_{2}$-sensitive material $\left(\mathrm{MoO}_{3}\right.$ and $\mathrm{Pd}$ catalyst) coated on a flexible plastic sheet that was pressed against the mouse skin directly above the implant. Although the $\mathrm{H}_{2}$ levels permeating through the skin during the degradation process were very low, the sensor changed color to give a
\end{abstract}


three dimensional (3D) visualization of $\mathrm{H}_{2}$ permeation. The correlation between the visual sensor response and measurements made with an electrochemical $\mathrm{H}_{2}$ microsensor on several magnesium alloys demonstrates that the visual sensor has the capability to monitor in real-time the dissolution rate of implants in vivo. This detection method is noninvasive, easy to implement, effective and potentially low cost compared to electrochemical detection.

\section{Statement of Significance}

Biodegradable Mg implants offer advantages over permanent implants such as stainless steel that are used for broken bone repair. Mg alloys gradually dissolve, avoiding the need for removal by a later surgery if complications arise. Here we report a visual $\mathrm{H}_{2}$ sensor that can be used in the research laboratory to monitor the corrosion process in vivo during animal testing of different $\mathrm{Mg}$ alloys. The sensor consists of a plastic sheet with a thin coating that changes color in the presence of $\mathrm{H}_{2}$ gas. The sensor is easily used by taping it on the skin over the $\mathrm{Mg}$ implant. The color change gives a map of the $\mathrm{H}_{2}$ level permeating from the degrading $\mathrm{Mg}$ through the skin above it. This low cost, simple method of monitoring the dissolution of biodegradable implants would greatly facilitate the development of the biodegradable materials, especially in animal studies where in vivo biodegradation is tested.

Keywords: Biodegradable implants, Magnesium alloys, Hydrogen, Visual sensor

\section{Introduction}

Metallic biomaterials play an essential role in replacement and repair of damaged or diseased hard tissues such as bone [1,2]. Currently, approved and commonly used metallic implant materials are stainless steels, cobalt-chromium based alloys, titanium and its alloys [1]. The mismatch between the mechanical properties of these metals and the surrounding natural bones results in stress shielding effects that can lead to bone resorption, reduced stimulation of the new 
bone growth, and remodeling $[3,4]$. At the same time, the release of toxic metal ions and/or particles such as chromium through corrosion or wear can cause inflammatory response that reduces the biocompatibility and causes tissue loss [5-8]. These metallic materials remain inside the body after implantation as permanent fixtures, which sometimes must be removed by a second surgical procedure after the tissue heals sufficiently due to complications such as pain $[1,9]$. Additional surgery increases cost to the health care system and causes more stress to the patient.

Biodegradable implants offer many advantages over the permanent implants used today. New implants based on biodegradable materials can adapt to the human body in which they are implanted and eventually dissolve when no longer needed. Mg alloys are a promising candidate for biodegradable implants due to their physical and mechanical properties being close to those of bone. $\mathrm{Mg}$ and $\mathrm{Mg}$ based alloys have higher yield strength and a lower elastic modulus around 45 Gpa, close to that of natural bone (3-20 GPa) $[10,11]$. These properties give them the potential to avoid stress-shielding effects $[9,12]$. Mg and its alloys are generally known to degrade in aqueous physiological environment via an electrochemical reaction (corrosion process). The primary anodic reaction is expressed by equation (1) where $\mathrm{Mg}$ oxidizes to solution soluble $\mathrm{Mg}^{2+}$, and the reduction of protons is expressed by the cathodic reaction (2), which generates hydrogen gas $\left(\mathrm{H}_{2}\right)$. $\mathrm{Mg}^{2+}$ generated in the anodic reaction reacts with hydroxide generated in the cathodic reaction to form $\mathrm{Mg}(\mathrm{OH})_{2}$ (3), unless the solution is adequately buffered. The overall corrosion reaction of $\mathrm{Mg}$ in aqueous environment is shown in equation (4).

$$
\begin{aligned}
& \mathrm{Mg}(\mathrm{s}) \longrightarrow \mathrm{Mg}^{2+}(\mathrm{aq})+2 \mathrm{e}^{-}(\text {anodic reaction) } \\
& 2 \mathrm{H}_{2} \mathrm{O}(\mathrm{aq})+2 \mathrm{e}^{-} \longrightarrow \mathrm{H}_{2}(\mathrm{~g})+2 \mathrm{OH}^{-}(\mathrm{aq}) \text { (cathodic reaction) } \\
& \mathrm{Mg}^{2+}(\mathrm{aq})+2 \mathrm{OH}^{-} \longrightarrow \mathrm{Mg}(\mathrm{OH})_{2}(\mathrm{~s}) \text { (product formation) } \\
& \mathrm{Mg}(\mathrm{s})+2 \mathrm{H}_{2} \mathrm{O} \longrightarrow \mathrm{Mg}(\mathrm{OH})_{2}(\mathrm{~s})+\mathrm{H}_{2}(\mathrm{~g})
\end{aligned}
$$


The most common ways to monitor the corrosion process in vitro are gravimetric measurements of $\mathrm{Mg}$ weight loss and electrochemical measurements such as linear polarization and electrochemical impedance spectroscopy [13-16]. As a non-destructive method microtomography, especially synchrotron-based microtomography, can be used to determine general corrosion rates by observing the time-dependent change in the metallic volume of the remaining implant [17]. However, the above techniques are time consuming or need large equipment such as an X-ray. One way to monitor the biodegradability of $\mathrm{Mg}$ and its alloys is by measuring $\mathrm{H}_{2}$ evolution. It is known that $\sim 1 \mathrm{~mL}$ of $\mathrm{H}_{2}$ evolved corresponds to $1 \mathrm{mg}$ of $\mathrm{Mg}$ dissolved [14, 18], and hence measuring $\mathrm{H}_{2}$ evolution rate is equivalent to measuring the biodegradation or corrosion rate of a $\mathrm{Mg}$ alloy. Unanodized and anodized $\mathrm{Mg}$ alloys usually exhibit localized corrosion and $\mathrm{H}_{2}$ mainly comes from the local corroding areas, which implies that the $\mathrm{H}_{2}$ evolution rate can reliably reflect the local degradation rate of a $\mathrm{Mg}$ alloy $[14,18,19]$. The evolution of $\mathrm{H}_{2}$ gas during $\mathrm{Mg}$ and its alloy corrosion in aqueous biological media $[13,14]$ and the resultant formation of gas cavities in vivo $[15,20-23]$ have been extensively observed. Therefore, measuring the volume of $\mathrm{H}_{2}$ gas generated during $\mathrm{Mg}$ corrosion to determine the corrosion rate has been studied in vivo or in vitro by several research groups [14, 18, 19, 22, 24-29]. However, the investigation of $\mathrm{Mg}$ and $\mathrm{Mg}$ alloys corrosion in vivo has been a challenge due to the various environmental factors such as the local blood flow, water content of the different tissues, local chloride content, and $\mathrm{H}_{2}$ diffusion coefficient [15]. Therefore, the development of simple sensors to monitor the corrosion process in vivo is desirable.

Our group has used an electrochemical (amperometric) $\mathrm{H}_{2}$ sensor to monitor the corrosion process of implanted rare earth-containing Mg alloys, other $\mathrm{Mg}$ alloys and high purity $\mathrm{Mg}$ single crystal disks in mice $[22,30,31]$. One study showed that there is little difference between the $\mathrm{H}_{2}$ 
concentration inside a gas cavity associated with a subcutaneous implant and a transdermal measurement made on the skin above the implant $[30,31]$. This observation confirmed the extraordinarily fast transport of $\mathrm{H}_{2}$ through biological tissues such as skin, which also means that $\mathrm{H}_{2}$ levels in vivo can potentially be tracked noninvasively by a $\mathrm{H}_{2}$ sensor measuring transdermally by simply pressing it against the skin. The correlation of the $\mathrm{H}_{2}$ measurement and corrosion rate by weight loss of the implants in vivo after two months confirms that non-invasive $\mathrm{H}_{2}$ sensing is an effective way to track in vivo biodegradation rates of $\mathrm{Mg}$ and $\mathrm{Mg}$ alloy implants $[22,30,31]$. $\mathrm{H}_{2}$ concentrations are higher for faster corroding implants compared to slower corroding systems under the same conditions [31]. Using the electrochemical sensor for transdermal $\mathrm{H}_{2}$ mapping of a mouse body also confirmed that the $\mathrm{H}_{2}$ concentration is highest above the gas cavity compared to areas adjacent to and far from the implant area $[22,30,31]$. Although the amperometric $\mathrm{H}_{2}$ microsensors are sensitive and respond rapidly, they are fragile, expensive, and require calibration before and after use. Also, the sensitivity decreases after using and the overall measurement is time consuming for point by point measurements. Therefore, a simple and effective method for monitoring the implant biodegradation process is needed for routine in vivo measurements.

Element One Inc. has developed materials for the detection of $\mathrm{H}_{2}$ that change color either reversibly or irrreversibly in the presence of $\mathrm{H}_{2}$ gas. The visual $\mathrm{H}_{2}$ indicator uses either thin films or nano particles of a transition metal oxide with a very thin, discontinuous coating of a catalyst to catalyze its reaction with $\mathrm{H}_{2}$ [32]. Originally developed for leak detection in $\mathrm{H}_{2}$ fueled vehicles, fuel power applications, as well as transportation pipe lines, the sensor is proving useful for other applications such as the first biomedical application described here.

Here we report an $\mathrm{H}_{2}$ visual sensor that was applied to monitor the $\mathrm{Mg}$ alloy corrosion process in vivo. This method provides a rapid, visual, non-invasive, quantitative, easily performed 
measurement of $\mathrm{H}_{2}$, which correlates with degradation rate of $\mathrm{Mg}$ alloys. This takes advantage of the degradation mechanism of the main metal component, $\mathrm{Mg}$, which generates $\mathrm{H}_{2}$ that permeates through the skin adjacent to the implant at a low level. This low cost, simple method of monitoring the dissolution of biodegradable implants would greatly facilitate the development of the biodegradable materials, especially in animal studies where in vivo biodegradation is tested. It also has the potential for clinical applications.

\section{Experimental}

\subsection{Description of $\mathrm{Mg}$ samples and visual sensor}

Mg alloy ZK40 (Mg-4 wt\%Zn-0.5 wt\%Zr) was prepared by a previously described method [33]. $\mathrm{Mg}$ alloy AZ31 (Mg-2.5-3.5 wt\%Al-0.6-1.4 wt\%Zn-0.2-1.0 wt\%Mn) was purchased from Goodfellow (Oakdale, PA). The processing of the alloy was based on a previous method [34]. Mg

alloys LZ61 (Mg-6\%Li-1\%Zn), LAZ611 (Mg-6\%Li-1\%Al-1\%Zn) and LAZ631 (Mg-6\%Li$3 \% \mathrm{Al}-1 \% \mathrm{Zn}$ ) were fabricated using a vacuum furnace to melt the alloys following casting and extrusion to generate rods of $20 \mathrm{~mm}$ diameter.

The visual $\mathrm{H}_{2}$ sensor is a flexible transparent plastic sheet on which layers of $350 \mathrm{~nm} \mathrm{MoO}, 2$ nm Pd nanoparticles, and $100 \mathrm{~nm}$ polytetrafluoroethylene were vacuum deposited. Small pieces were cut from the larger sheets to use in the experiments described here.

\subsection{Procedures on laboratory mice}

Specific pathogen-free female athymic nude mice were purchased from Harlan Laboratory (Indianapolis, IN) and used in the study when they were 8 to 10 weeks of age. The mice were maintained in a facility approved by the American Association for Accreditation of Laboratory Animal Care and in accordance with current regulations and standards of the U.S. Department of Agriculture, U.S. Department of Health and Human Services, and NIH. The animal studies were 
approved by the Institutional Animal Care and Use Committee (IACUC) and executed according to IACUC guidelines. An in vivo murine subcutaneous study was conducted to explore any acute host response of AZ31, ZK40, LZA631, LAZ611 and LZ61 samples. Implantation into mice (3 mice/sample type) was performed at the University of Cincinnati. For this test, discs of $5 \mathrm{~mm}$ diameter and $1.4 \mathrm{~mm}$ thickness were sectioned from the AZ31, ZK40, LZA631, LAZ611 and LZ61 alloy specimens. The disc samples were then sonicated in acetone and air dried. For sterilization, the pellets were placed in $70 \%$ ethanol for 5 min, rinsed with Dulbecco's phosphate buffer saline (DPBS, $\mathrm{KCl} 2.7 \mathrm{mM}, \mathrm{KH}_{2} \mathrm{PO}_{4}(1.5 \mathrm{mM}), \mathrm{NaCl}(138 \mathrm{mM}), \mathrm{Na}_{2} \mathrm{HPO}_{4}$ anhydrous (8.1 mM), pH 7.0) and then irradiated under UV light for 20 min on each side of the discs. Healthy nude mice were housed under controlled conditions and maintained with a standard diet and water. All the mice were anesthetized with isoflurane and a small skin incision was made to create a subcutaneous pocket on the back of the mouse. Mg alloys were inserted into the pocket, and the incision was closed with surgical staples. Control mice were not subjected to any implant, but were also living in the same conditions for the same experimental time as the mice with implants. When the study was completed after 2 months, the mice were sacrificed in $\mathrm{CO}_{2}$ chamber, followed by cervical dislocation.

\section{3. $\mathrm{H}_{2}$ measurement by amperometric $\mathrm{H}_{2}$ sensor}

Amperometric $\mathrm{H}_{2}$ measurements were performed using a $\mathrm{H}_{2}$ microsensor (50 $\mu \mathrm{m}$ tip diameter) connected to a multi/meter (both from Unisense, Aarhus, Denmark) polarized at $+1000 \mathrm{mV}$ for at least $1 \mathrm{~h}$ [35]. Before each series of measurements, the $\mathrm{H}_{2}$ microsensor was calibrated following the manufacturer's recommendations [35]. For calibration, high purity $\mathrm{H}_{2}$ gas was bubbled through water until $\mathrm{H}_{2}$ saturation was reached. Then, the saturated $\mathrm{H}_{2}$ water solution was diluted to various concentrations with deionized water (0-100\%). The diluted $\mathrm{H}_{2}$ concentrations were calculated 
based on their percentages based on the $\mathrm{H}_{2}$ saturated water solution [35, 36]. For each measurement, the $\mathrm{H}_{2}$ sensor tip was in the $\mathrm{H}_{2}$ water solution for 3 min. The steady state current was calculated from the average of the steady state signal data points taken during each measurement. A current vs. $\mathrm{H}_{2}$ concentration calibration curve was plotted and then used to convert instrument readings to $\mathrm{H}_{2}$ concentration for the in vivo measurements on mice.

For in vivo measurements, anesthetized mice were immobilized on a heated swiveling table. The microsensor was positioned with a micromanipulator [22, 30, 31]. Measurements were taken by touching the sensor tip on the skin above the gas cavity near the implant area. As a control, measurements were taken on the skin in areas remote from the gas cavities. The current obtained from the $\mathrm{H}_{2}$ sensor was converted to $\mathrm{H}_{2}$ concentration using the calibration curve generated from known levels of $\mathrm{H}_{2}$ saturated water.

\section{4. $\mathrm{H}_{2}$ measurement by visual sensor}

Visual $\mathrm{H}_{2}$ sensors were provided by Element One in the form of $21 \mathrm{~cm}$ by $28 \mathrm{~cm}$ sheets with the chromogenic agent applied as an array of dots with a diameter of $0.6 \mathrm{~cm}$. A small section is shown in Fig.1a. Visual sensors for each measurement were prepared by cutting pieces with one or more dots from the larger sheet of the visual sensors. The $\mathrm{H}_{2}$ visual sensor was used by positioning the middle of a dot centered directly above a Mg sample implanted under the skin of an anesthetized mouse or in the center of the gas cavity if a cavity was visible. Digital photographs of the visual sensor color development were taken at certain intervals to monitor the corrosion process.

ImageJ is a public domain, Java-based image processing program inspired by National Institutes of Health (NIH). The imageJ software (version 1.50f) was used to quantify the color changes in photographs associated with different levels of $\mathrm{H}_{2}$ generated from the biodegradation 
of $\mathrm{Mg}$ alloy implants. With the selection of the dark area in the images, the quantified results are calculated using the brightness values. The pixels are converted to brightness values using the formula value $=($ red + green + blue $) / 3$ by ImageJ. With the area selections, the mean brightness value was used to quantify the color change with the time difference. The standard deviation of the brightness values was calculated by ImageJ for the selected color changing area.

\subsection{Weight loss measurements}

The procedure for weight measurement follows our recently reported method [22, 37]. The explanted alloys were cleaned by immersing in chromate solution containing $200 \mathrm{~g} / \mathrm{L} \mathrm{CrO}_{3}$ at room temperature for $10 \mathrm{~min}$ in order to remove the formed products on the surface. The cleaned explanted alloys were weighed. The difference between the mass of the sample before corrosion and the mass of the alloys after cleaning was considered to be the total mass loss.

\subsection{Statistical analysis}

For statistical analysis of $\mathrm{H}_{2}$ generated by the magnesium alloy corrosion, measurements were made on 3 mice per sample type and control. The statistical analysis for brightness measurement was performed using GraphPad Prism 3 software (GraphPad Prism Software, Inc.). Statistical significance of difference between groups was assessed by one-way analysis of variance (ANOVA) followed by post hoc Tukey's multiple comparison test. The significance of differences was evaluated by the Student $t$-test. $P$ values less than 0.05 were considered statistically significant.

\section{Results and Discussion}

\section{1. $\mathrm{H}_{2}$ visual sensor}

The visual $\mathrm{H}_{2}$ sensor consists of a flexible plastic sheet with a thin coating on one side that undergoes a color change from gray to dark blue upon exposure to $\mathrm{H}_{2}$. The sensing mechanism 
involves reduction of the metal oxide $\mathrm{MoO}_{3}$ by $\mathrm{H}_{2}$ in the presence of the metal catalyst $\mathrm{Pd}$ [38-40]. $\mathrm{H}_{2}$ gas is dissociated at room temperature on the surface of Pd catalyst into $\mathrm{H}$ atoms (Eq. 1) that diffuse into the underlying transition metal oxide film to reduce $\mathrm{MoO}_{3}$ causing it to change color to hydrogen molybdenum bronze (Eq. 2). The reaction mechanism can be written as follows:

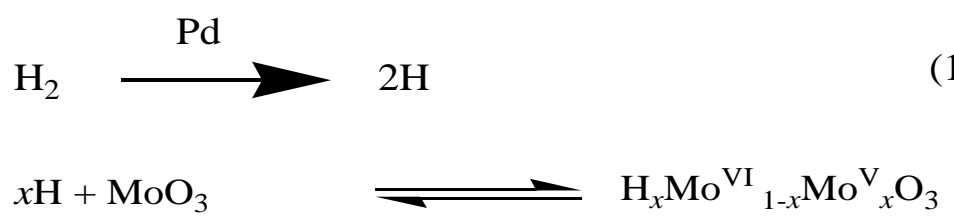

The sensor is easily used by taping it on the skin over the $\mathrm{Mg}$ implant. The color change gives a map of the $\mathrm{H}_{2}$ level permeating from the biodegrading $\mathrm{Mg}$ through the skin above it.

The measurement of $\mathrm{H}_{2}$ permeating through the skin with a visual sensor for the purpose of monitoring corrosion of a biodegradable metal device is unique. Fig. 1a shows a piece of visual $\mathrm{H}_{2}$ sensor sheet that consists of an array of $\mathrm{H}_{2}$ sensitive gray dots. This piece was taped to a mouse so that the center dot was positioned directly above a Mg sample (alloy ZK40) implanted under the skin of the anesthetized mouse. The color evolved with time and was fully developed after 160 min for this alloy. The visual sensor color is gray before exposure to $\mathrm{H}_{2}$ (Fig. 1a), changing to dark blue or black (Fig. 1b) after 160 min exposure to $\mathrm{H}_{2}$ generated by ZK40. The complete color change of the center dot and the partial change of the surrounding dots defines the region of $\mathrm{H}_{2}$ permeation from the implanted alloy through the skin. From the picture, it is clearly seen that the color density of the visual sensor in the center dot is much darker than the edge area. This shows that the $\mathrm{H}_{2}$ permeation rate through the mouse skin concentration is higher at the center of the gas cavity than the edge area, which is consistent with our previously reported results using an amperometric $\mathrm{H}_{2}$ sensor $[30,31]$. In that previous study and this present study, the $\mathrm{H}_{2}$ levels permeating through the skin during the degradation process were found to be of very low 
concentration, requiring very good sensitivity for detection. This experiment herein shows that the thin film visual $\mathrm{H}_{2}$ sensor is capable of detecting transdermally the low levels of $\mathrm{H}_{2}$ associated with the biodegradation of the sample of $\mathrm{Mg}$ implant implanted in a laboratory animal. The area in which the color response occurs also gives a two-dimensional visual assessment of the $\mathrm{H}_{2}$ emitting region of the mouse. By comparison, the amperometric $\mathrm{H}_{2}$ sensor requires that measurements be made point by point, making it much more time consuming and difficult to map the $\mathrm{H}_{2}$ permeation area.

Figure 2 illustrates the use of a single dot of the visual $\mathrm{H}_{2}$ sensor that is centered over the $\mathrm{Mg}$ implant. It shows a uniform color change from gray to dark blue (even black) after exposure to $\mathrm{H}_{2}$ permeating through the mouse skin. A more slowly corroding Mg alloy, LAZ631, was used for this study and it took a longer time for the color (Fig. 2b) to fully develop: $213 \mathrm{~min}$.

The visual $\mathrm{H}_{2}$ sensor quantitatively responses to the amount of $\mathrm{H}_{2}$ to which it is exposed, which in this application is the concentration at the surface of the mouse skin combined with the exposure time. As such the sensor is responding to the permeation of $\mathrm{H}_{2}$ from the gas cavity through the skin. Thus, the sensor is responding to the real-time corrosion rate of the implanted alloy as reflected by the $\mathrm{H}_{2}$ level in the gas cavity. The sensor only detects the $\mathrm{H}_{2}$ permeating through the skin that is directly in contact with the skin's surface. The permeation of gas through the tissue surrounding the implant is three-dimensional. The sensor does not respond to $\mathrm{H}_{2}$ that permeates into the animal and is transported away by the blood. Moreover, part of the $\mathrm{H}_{2}$ permeating through the skin beneath the sensor escapes to the air due to the uneven boundary between the smooth sensor surface and wrinkled skin. Since the sensor does not absorb all of the $\mathrm{H}_{2}$ evolved by the $\mathrm{Mg}$ implant and so is not a quantitative measure of the total amount of $\mathrm{H}_{2}$ released by the biodegradation process, it is not quantitatively measuring the overall corrosion rate in $\mathrm{mm} / \mathrm{y}$ in the 
usual sense that collecting the total volume of $\mathrm{H}_{2}$ released or measuring the weight-loss of explanted samples provides. Instead, the visual $\mathrm{H}_{2}$ sensor affords a platform for an in vivo measurement of the real-time corrosion rate. Thus, the sensor complements rather than replaces the existing techniques of total $\mathrm{H}_{2}$ volume or sample weight-loss measurements that give an overall, averaged corrosion rate over the entire duration of the implant. The real-time measurements enable one to determine how corrosion rate changes during the time-course of an implant experiment, which cannot be done with the standard techniques.

The sensor is $0.6 \mathrm{~cm}$ in diameter, which fully covers the whole implant. The darkest part corresponds to the highest $\mathrm{H}_{2}$ level section, which is usually the center of the gas cavity rather than the center of the implant (the two can be different). We found it to be difficult to put the $\mathrm{H}_{2}$ visual sensor directly above the implant for every mouse because skin movement causes the sensor to change its position relative to the position of the implant. Therefore, the centers of the visual sensors are not necessarily darkest.

Since the sensor color darkens with increased exposure to $\mathrm{H}_{2}$, there are two means for measuring the concentration of $\mathrm{H}_{2}$ at the skin. In the first method, which we used in this study, the sensors are exposed to the skin for a fixed period of time and the final sensor color is proportional to the concentration of $\mathrm{H}_{2}$. In the second, all of the sensors are left in contact with the skin until a predetermined color change has occurred. Here the time required to achieve that color is proportional to the concentration of $\mathrm{H}_{2}$ being measured. The color of the $\mathrm{H}_{2}$ visual sensor does not continue to change once it has reached saturation and all of the color-sensitive material has reacted with $\mathrm{H}_{2}$.

The visual sensor is very selective for hydrogen. It only responds to gases that can penetrate the outer protective layer and that are also sufficiently strong reducing agents to react with the color- 
sensitive material in the film. Ordinary air contains nothing at an appreciable level that is capable of reacting with the color-sensitive material besides a trace amount of $\mathrm{H}_{2}\left(5.50 \times 10^{-5}\right.$, vol \%) [41]. This concentration of $\mathrm{H}_{2}$ is too low to cause a color change in a relevant period of time. We have left samples of the visual sensor on the laboratory bench for up to a year with no measureable change in color. For this application of in vivo measurements, the only gas that would be expected to permeate through the skin of a control mouse with no $\mathrm{Mg}$ implant and that can change the color of the sensor is the residual level of $\mathrm{H}_{2}$ that is present in mice (and other animals) from the digestive process. This level has been reported to be in the range of 1.0-7.3 $\mu \mathrm{M}$ for $\mathrm{H}_{2}$ generated from aerobic bacteria in the food digestion process [31, 42], which is well below the $\mathrm{H}_{2}$ levels associated with Mg biodegradation that are being measured here. In our experiments, this background level of endogenous $\mathrm{H}_{2}$ was found to be too low to cause a measureable color change in visual $\mathrm{H}_{2}$ sensors that were taped on the control mice with no implant for up to $6 \mathrm{~h}$. This time exceeds the time frame needed of our measurements in this work, which were only up to $4 \mathrm{~h}$. We attempted to determine how long it would take for the visual sensor to begin detecting the natural $\mathrm{H}_{2}$ levels from the control mice. However, we were unsuccessful because when awake, the mice always attempt to scratch off the $\mathrm{H}_{2}$ visual sensor, which prevented measurements for a sufficiently long period to answer this question. The mice cannot be left anesthetized for a sufficiently long period to make the measurement. Nonetheless, this "background" level of $\mathrm{H}_{2}$ ultimately determines the sensitivity of the visual sensor for monitoring corrosion of an implant. If the biodegradation is too slow or if the implant is too deep, insufficient $\mathrm{H}_{2}$ will reach the skin surface to be distinguished from this naturally occurring background level.

\subsection{Progression of sensor response to alloys with varying biodegradation rates}


The progression of color response for the biodegradation process of alloys with varying rates of biodegradation was explored to determine the relationship between sensor response and biodegradation rate. Figure 3a shows results for a more slowly corroding Mg alloy, LAZ631, in vivo. The color development begins first in the region of the skin with greatest $\mathrm{H}_{2}$ permeation as seen by the localized region of color development in the $70 \mathrm{~min}$ dot. The color of the entire dot became blue at $105 \mathrm{~min}$. The overall color in the dot became progressively darker with increasing exposure time with complete color development being reached after about four hours. The color response integrates the exposure with time to $\mathrm{H}_{2}$ permeating through the skin during the degradation process. The sensors thus can clearly detect the $\mathrm{H}_{2}$ levels even though the very low concentration associated with this more slowly corroding alloy requires very good sensitivity for detection $[22,30,31]$. The obvious color changes with such low $\mathrm{H}_{2}$ concentrations indicate that this visual sensor has sufficiently high sensitivity to detect transdermally the very low levels of $\mathrm{H}_{2}$ associated with the biodegradation of a sample of $\mathrm{Mg}$ implanted in the laboratory animal. The area in which the color response occurs gives a visual assessment of the $\mathrm{H}_{2}$ emitting region of the mouse. Since the measurement is real-time, the results show that the LAZ631 implant was actively undergoing corrosion in vivo at the time of the measurement. Although the color change does not measure the total $\mathrm{H}_{2}$ volume evolved, the color response correlates to the $\mathrm{H}_{2}$ concentration in the gas cavity. It exhibits the real time monitoring of the corrosion of $\mathrm{Mg}$ implants, which is a supplement measurement technique that can now be used in addition to other in vivo measurements such as micro-CT.

The variation in intensity of the color change over the area of the dot can be used to generate a three dimensional (3D) plot such as shown in Fig 3b where two dimensions are area and the third is color intensity (or $\mathrm{H}_{2}$ concentration). The vertical axis displays the $\mathrm{H}_{2}$ concentration in the region 
being sampled in terms of the adjacent vertical color scale, which also has a concentration scale to aid the reader in translating color into concentration measured by the sensor. The 3D figure of the $\mathrm{H}_{2}$ sensor color development was generated by 3D surface plot (Image $J$ ) which measures the brightness of the dot from a digital image. The brightness of the unexposed area of the dot is represented as orange; more intense blue means a darker dot (decreasing brightness). The figure shows that the brightness of the dot gradually decreases from the edge area to the center with $\mathrm{H}_{2}$ sensor exposure to the $\mathrm{H}_{2}$ transdermally permeating from the biodegradation of LAZ631 alloy. The 3D figure also shows that the $\mathrm{H}_{2}$ concentration is highest at the center of the alloy compared to the edge area, and area far from the implant. This observation is consistent with our $\mathrm{H}_{2}$ microsensor measurements [30, 31]. This 3D capability should be useful in visually assessing the real-time biodegradation of specific sections of larger Mg alloy devices that are implanted.

The difference in the color development with $\mathrm{H}_{2}$ concentration enabled us to use the mean brightness value of a selected area as an indicator to evaluate the $\mathrm{H}_{2}$ responses to different alloys. To evaluate the quantitative color response to $\mathrm{H}_{2}$ permeating through the skin, the brightness of the pictures was evaluated by ImageJ. The correlation of the brightness and the exposure time is plotted in Fig. 3c. The correlation equation is $y=-0.33 x+117.3\left(R^{2}=0.89\right)$ where $y$ is brightness in pixels and $x$ is time in minutes. It can be seen that the brightness of the $\mathrm{H}_{2}$ sensor decreases linearly with increasing exposure time until the $\mathrm{H}_{2}$ sensor film reaches the saturation state. Therefore, the color response can be used as a tool to correlate either the brightness at a fixed exposure time, or the time to achieve a specified brightness, with the $\mathrm{H}_{2}$ level permeating through the skin.

The visual sensors were also tested with three other alloys exhibiting different corrosion rates - LAZ611, LZ61 and AZ31, and the results are shown in Figures 4, 5, and 6, respectively. In the 
case of a LAZ611 alloy implant (Fig. 4a), the color change is first visible at $90 \mathrm{~min}$ and the color developed to darker shades with continuing exposure time. In the case of LZ61 (Fig. 5) and AZ31 implants (Fig. 6), a visible color change was observed too, although it takes a longer time because they biodegrade more slowly. The correlation equations of the color brightness and the exposure time are $\mathrm{y}=-0.23 x+124.5\left(\mathrm{R}^{2}=0.80\right)($ Fig. $4 \mathrm{~b}), \mathrm{y}=-0.14 x+122.4\left(\mathrm{R}^{2}=0.94\right)($ Fig. $5 \mathrm{~b})$ and $\mathrm{y}=$ $-0.13 x+123.2\left(\mathrm{R}^{2}=0.89\right)($ Fig. 6b) for LAZ611, LZ61 and AZ31, respectively. It is clearly seen that the brightness of the $\mathrm{H}_{2}$ visual sensor sensitivity for the four alloys evaluated is in the order of LAZ631 > LAZ611 > LZ61 ₹AZ31, which also reflects the order of the corrosion rate by weight loss after 2 months (LA631, 6.4\%, LAZ611, 4.5\%, LAZ61: 2.3\%, AZ31, 1.9\%).

Figure 7a shows the comparison among these different alloys at a certain exposure time interval. It is clearly seen that the color is darkest for LAZ631 at $230 \mathrm{~min}$, lighter for LAZ611 and LZ61 at $230 \mathrm{~min}$, and even lighter at $240 \mathrm{~min}$ for AZ31. These results are expressed in terms of color brightness comparison in Fig. 7b. The brightness measurements give a more quantitative comparison that generally agrees with the visual evaluation of the color intensities in Fig. 6a. The results are consistent with the order of the corrosion rate for the alloys as determined by weight loss: LAZ631 > LAZ611 > LZ61 ₹AZ31. The brightness decreases faster with the higher corrosion rate as shown by the bar graph of the slopes of the response plots for each alloy (Fig.7c). Even though the corrosion rate for AZ31 is very slow, the visual sensor is sufficiently sensitive to monitor the corrosion process. Therefore, this visual sensor can be used as an indicator to monitor the corrosion processes occurring in vivo, even though the measurement itself is noninvasive. It gives the corrosion rate occurring at the time of measurement. More quantitative results can be obtained with a simple program that measures the brightness of the circle.

\subsection{Correlation of $\mathrm{H}_{2}$ visual sensor with electrochemical $\mathrm{H}_{2}$ microsensor}


We have reported previously on the use of an extremely sensitive electrochemical (amperometric) $\mathrm{H}_{2}$ microsensor for transdermal measurements of $\mathrm{H}_{2}$ associated with in vivo corrosion of Mg alloys [22, 30, 31, 43]. In order to correlate the color response of the visual sensor with $\mathrm{H}_{2}$ concentrations measured electrochemically, in vivo measurements were made with both the visual $\mathrm{H}_{2}$ sensor and a calibrated electrochemical $\mathrm{H}_{2}$ sensor. Each mouse was first tested with the visual sensor as described above. The sheet of visual sensor was then removed and measurements were made on the same spot with the electrochemical sensor. $\mathrm{A}_{2}$ microsensor with a $50 \mu \mathrm{m}$ tip diameter was used for the amperometric measurements following our previously described procedures including calibration with standard $\mathrm{H}_{2}$ solutions [22, 30, 31]. The $\mathrm{H}_{2}$ microsensor was mounted in a micromanipulator and the tip positioned on top of the implant area of the nude mouse to make each measurement. $\mathrm{H}_{2}$ concentrations measured directly above the implants were $287 \pm 44 \mu \mathrm{M}, 138 \pm 30 \mu \mathrm{M}, 75 \pm 20$ and $36 \pm 12 \mu \mathrm{M}$ for LAZ631, LAZ611 and AZ31, respectively (Fig. 8a). The alloy LAZ631 shows the highest $\mathrm{H}_{2}$ concentration, followed by LAZ611 and AZ31, which agrees with the longer response time of the visual $\mathrm{H}_{2}$ sensor in the order of $\mathrm{AZ31} \approx \mathrm{LAZ611< \textrm {LAZ631. } .}$

The electrochemical sensor was used to establish a quantitative relationship between the color response of the visual $\mathrm{H}_{2}$ sensor and actual $\mathrm{H}_{2}$ concentrations relevant to this biomedical application. This was obtained via a calibration curve in which the digitally analyzed visual color (brightness) is plotted against $\mathrm{H}_{2}$ concentration determined by the calibrated amperometric $\mathrm{H}_{2}$ sensor. The correlation of the measured $\mathrm{H}_{2}$ concentration and the associated color brightness changes for the visual $\mathrm{H}_{2}$ sensor is plotted in Fig. $8 b$. The correlation equation is $\mathrm{y}=-0.22 x+103.6$ $\left(\mathrm{R}^{2}=0.91\right)$, where $y$ is brightness in pixels and $x$ is the $\mathrm{H}_{2}$ concentration in $\mu \mathrm{M}$. As seen from the calibration curve, the brightness decreases linearly with the increase in the $\mathrm{H}_{2}$ concentration. 
Therefore, quantization of the color response of the $\mathrm{H}_{2}$ visual sensor can be easily established by this calibration curve.

\section{Conclusion}

The sensitivity of the visual $\mathrm{H}_{2}$ sensor is adequate for monitoring the $\mathrm{Mg}$ biodegradation process in mouse subcutaneous implants. The visual sensor is a simple device that is easily used for animal studies. It gives a map of the $\mathrm{H}_{2}$ permeation region where brightness changes are easily quantified by computer using the ImageJ software. This application provides developers of biodegradable implants with the capability to easily monitor the rate of biodegradation with minimal impact on the recipient of the implant, especially in current animal studies in vivo. Although the sensor does not measure the overall $\mathrm{H}_{2}$ evolved over the time period of the implant, it can quantitatively measure the $\mathrm{H}_{2}$ concentration in the gas cavity, especially for the faster corroding implants. The visual $\mathrm{H}_{2}$ sensor gives the measurement of corrosion rate at the time of measurement rather than integrated over the entire time of implantation. Information from the visual sensor complements information about gas volume provided by other methods such as X-ray imaging and micro-CT for monitoring the Mg biodegradation process in vivo. However, the visual sensor method is easier, simpler, requires no expensive instrumentation and specially trained operating personnel, and poses no risk of exposure to X-rays, making it in some respects advantageous over these more established techniques. The main disadvantage of the sensor at this stage of development is the relatively long time required for color changes to occur at the very low levels of $\mathrm{H}_{2}$ permeating through the skin in these kinds of animal studies.

The $\mathrm{H}_{2}$ microsensor results also suggest that a more rapidly darkening area of the spot may correspond to a region of higher $\mathrm{H}_{2}$ evolution where a portion of the implant may be dissolving more rapidly for reasons such as stress concentration or a higher localized corrosive environment 
due to the chemical concentration of the ions in solution affecting the $\mathrm{pH}$ contributing to the corrosion of the $\mathrm{Mg}$ alloy. This type of localized corrosion information may be useful in the mechanical design process during development of an implant or may provide warning of dangerously rapid localized dissolution thus warranting change in the alloy design, microstructure as well as the resulting implant dimensions.

In this work we calibrated the visual sensors versus our calibrated electrochemical amperometric sensor, which has the disadvantage of adding an additional steps to the procedure, requires the electrochemical sensor and $\mathrm{H}_{2}$ standards. However, each batch of sensor sheets could be calibrated when they are fabricated by the manufacturer. In this case the user would receive a standard color chart for calibration from the manufacturer, eliminating the need for the electrochemical sensor and $\mathrm{H}_{2}$ standards. This would be similar to $\mathrm{pH}$ paper used to measure the $\mathrm{pH}$ of solutions from the color change. Precalibrated sensors sheets were not available at this early stage of development.

Hydrogen sensors such as this visual $\mathrm{H}_{2}$ sensor and the previously reported electrochemical $\mathrm{H}_{2}$ sensor $[22,30,31,43]$ provide an avenue for studying the early phase of biodegradation corrosion by monitoring $\mathrm{H}_{2}$ transdermally. This could lead to a better understanding of the in vivo biodegradation mechanism of $\mathrm{Mg}$ alloys. Measurements would be made at more frequent time intervals beginning immediately after implanting the alloy. The main challenge will be to make the measurements without anesthetizing the mice (which could not be done at such frequent intervals in this study) since they like to scratch off the visual sensor material. However, strategies for improving the adhesion of the sensor should deal with this issue.

The thin film visual sensor also has the potential for application to test animals larger than mice and to patients. The sensor would need adequate sensitivity for each application where the 
concentration of $\mathrm{H}_{2}$ at the skin surface would depend on the biodegradation rate of the implant as well as the depth of the implant and the permeability of the intervening tissue to $\mathrm{H}_{2}$. The sensitivity for $\mathrm{H}_{2}$ visual sensor is low at present, which requires longer exposure time to cause the color change. The main limitation of sensing $\mathrm{H}_{2}$ transdermally by the visual sensor is the maximum depth from the implant to skin surface and permeability of the biological tissue above the implant. The "background" level of endogenous $\mathrm{H}_{2}$ ultimately determines the sensitivity of the visual sensor for monitoring biodegradation of an implant. If the biodegradation is too slow or if the implant is too deep, insufficient $\mathrm{H}_{2}$ will reach the skin surface to be distinguished from this naturally occurring background level. Therefore, this sensor might not be used for deep implant biodegradation monitoring, such as the thigh bone where $\mathrm{H}_{2}$ has to permeate a thick muscle and skin to reach the sensor. Moreover, the performance of the sensor is expected to vary among the mammals due to their physical difference such as the skin thickness and different permeability of the tissues.

\section{Acknowledgement}

The authors thank the National Science Foundation for financial support (NSF ERC 0812348). PNK also acknowledges the support of the Edward R. Weidlein Chair Professorship Funds.

\section{Reference}

[1] M.P. Staiger, A.M. Pietak, J. Huadmai, G. Dias, Magnesium and its alloys as orthopedic biomaterials: A review, Biomaterials, 27 (2006) 1728-1734.

[2] M. Niinomi, Recent metallic materials for biomedical applications, Metall. Mater. Trans. A, 33 (2002) 477-486. 
[3] J. Nagels, M. Stokdijk, P.M. Rozing, Stress shielding and bone resorption in shoulder arthroplasty, J. Shoulder Elb. Surg., 12 (2003) 35-39.

[4] A.M. Rashmirraven, D.C. Richardson, H.M. Aberman, D.J. Deyoung, The response of cancellous and cortical canine bone to hydroxylapatite-coated and uncoated titanium rods, J. Appl. Biomater., 6 (1995) 237-242.

[5] D.R. Haynes, S.J. Boyle, S.D. Rogers, D.W. Howie, B. Vernon-Roberts, Variation in cytokines induced by particles from different prosthetic materials, Clin. Orthop. Relat. R., DOI (1998) 223-230.

[6] C. Lhotka, T. Szekeres, I. Steffan, K. Zhuber, K. Zweymuller, Four-year study of cobalt and chromium blood levels in patients managed with two different metal-on-metal total hip replacements, J. Orthopaed. Res., 21 (2003) 189-195. [7] J. Wang, B.H. Wicklund, R.B. Gustilo, D.T. Tsukayama, Titanium, chromium and cobalt ions modulate the release of bone-associated cytokines by human monocytes/macrophages in vitro, Biomaterials, 17 (1996) 2233-2240.

[8] Y. Niki, H. Matsumoto, Y. Suda, T. Otani, K. Fujikawa, Y. Toyama, N. Hisamori, A. Nozue, Metal ions induce bone-resorbing cytokine production through the redox pathway in synoviocytes and bone marrow macrophages, Biomaterials, 24 (2003) 1447-1457.

[9] P.R. Cha, H.S. Han, G.F. Yang, Y.C. Kim, K.H. Hong, S.C. Lee, J.Y. Jung, J.P. Ahn, Y.Y. Kim, S.Y. Cho, J.Y. Byun, K.S. Lee, S.J. Yang, H.K. Seok, Biodegradability engineering of biodegradable $\mathrm{Mg}$ alloys: Tailoring the electrochemical properties and microstructure of constituent phases, Sci. Rep., 3 (2013) 2367. [10] M. Razavi, M.H. Fathi, M. Meratian, Microstructure, mechanical properties and bio-corrosion evaluation of biodegradable AZ91-FA nanocomposites for biomedical applications, Mat. Sci. Eng. a-Struct., 527 (2010) 6938-6944.

[11] A. Feng, Y. Han, The microstructure, mechanical and corrosion properties of calcium polyphosphate reinforced ZK60A magnesium alloy composites, J. Alloy. Compd., 504 (2010) 585-593.

[12] E. Zhang, L.P. Xu, K. Yang, Formation by ion plating of Ti-coating on pure Mg for biomedical applications, Scripta Mater., 53 (2005) 523-527.

[13] G. Song, A. Atrens, Corrosion mechanisms of magnesium alloys, Adv. Eng. Mater., 1 (1999) 11-33.

[14] G. Song, Recent progress in corrosion and protection of magnesium alloys, Adv. Eng. Mater., 7 (2005) 563-586.

[15] F. Witte, N. Hort, C. Vogt, S. Cohen, K.U. Kainer, R. Willumeit, F. Feyerabend, Degradable biomaterials based on magnesium corrosion, Curr. Opin. Solid St. M., 12 (2008) 63-72.

[16] G. Song, A. Atrens, Understanding magnesium corrosion - A framework for improved alloy performance, Adv. Eng. Mater., 5 (2003) 837-858. 
[17] F. Witte, J. Fischer, J. Nellesen, H.A. Crostack, V. Kaese, A. Pisch, F. Beckmann, $\mathrm{H}$. Windhagen, In vitro and in vivo corrosion measurements of magnesium alloys, Biomaterials, 27 (2006) 1013-1018.

[18] G. Song, Control of biodegradation of biocompatable magnesium alloys, Corros. Sci., 49 (2007) 1696-1701.

[19] G. Song, S. Song, A possible biodegradable magnesium implant material, Adv. Eng. Mater., 9 (2007) 298-302.

[20] N. Von Der Hoh, D. Bormann, A. Lucas, B. Denkena, C. Hackenbroich, A. Meyer-Lindenberg, Influence of different surface machining treatments of magnesium-based resorbable implants on the degradation behavior in rabbits, Adv. Eng. Mater., 11 (2009) B47-B54.

[21] R.A. Kaya, H. Cavusoglu, C. Tanik, A.A. Kaya, O. Duygulu, Z. Mutlu, E. Zengin, Y. Aydin, The effects of magnesium particles in posterolateral spinal fusion: an experimental in vivo study in a sheep model, J. Neurosurg-Spine, 6 (2007) 141149.

[22] J. Kuhlmann, I. Bartsch, E. Willbold, S. Schuchardt, O. Holz, N. Hort, D. Hoche, W.R. Heineman, F. Witte, Fast escape of hydrogen from gas cavities around corroding magnesium implants, Acta Biomater., 9 (2013) 8714-8721.

[23] F. Witte, V. Kaese, H. Haferkamp, E. Switzer, A. Meyer-Lindenberg, C.J. Wirth, H. Windhagen, In vivo corrosion of four magnesium alloys and the associated bone response, Biomaterials, 26 (2005) 3557-3563.

[24] G.L. Makar, J. Kruger, Corrosion of magnesium, Int. Mater. Rev., 38 (1993) 138-153.

[25] G.L. Makar, J. Kruger, Corrosion studies of rapidly solidified magnesium alloys, J. Electrochem. Soc., 137 (1990) 414-421.

[26] F. Witte, J. Fischer, J. Nellesen, C. Vogt, J. Vogt, T. Donath, F. Beckmann, In vivo corrosion and corrosion protection of magnesium alloy LAE442, Acta Biomater., 6 (2010) 1792-1799.

[27] Z. Shi, M. Liu, A. Atrens, Measurement of the corrosion rate of magnesium alloys using Tafel extrapolation, Corros. Sci., 52 (2010) 579-588.

[28] Y.S. Choi, Y. Zhang, M. Xu, Y. Yang, M. Ito, T. Peng, Z. Cui, A. Nagy, A.K. Hadjantonakis, R.A. Lang, G. Cotsarelis, T. Andl, E.E. Morrisey, S.E. Millar, Distinct functions for Wnt/beta-Catenin in hair follicle stem cell proliferation and survival and interfollicular epidermal homeostasis, Cell Stem Cell, 13 (2013) 720-733.

[29] Y. Yang, C. Han, GDNF stimulates the proliferation of cultured mouse immature Sertoli cells via its receptor subunit NCAM and ERK1/2 signaling pathway, BMC Cell Biol., 11 (2010) 78. 
[30] D. Zhao, T. Wang, X. Guo, J. Kuhlmann, A. Doepke, Z. Dong, V.N. Shanov, W.R. Heineman, Monitoring biodegradation of magnesium implants with sensors, JOM-J. Min. Met. S., 68 (2016) 1204-1208.

[31] D. Zhao, T. Wang, J. Kuhlmann, Z. Dong, S. Chen, M. Joshi, P. Salunke, V.N. Shanov, D. Hong, P.N. Kumta, W.R. Heineman, In vivo monitoring the biodegradation of magnesium alloys with an electrochemical $\mathrm{H}_{2}$ sensor Acta Biomater., 36 (2016) 361-368.

[32] W. Hoagland, Hydrogen gas indicator system, U.S. patent 6895805, USA 2005.

[33] D. Hong, P. Saha, D. Chou, B. Lee, B.E. Collins, Z. Tan, Z. Dong, P.N. Kumta, In vitro degradation and cytotoxicity response of Mg-4\% Zn-0.5\% Zr (ZK40) alloy as a potential biodegradable material, Acta Biomater., 9 (2013) 8534-8547.

[34] D. Chou, D. Hong, P. Saha, J. Ferrero, B. Lee, Z. Tan, Z. Dong, P.N. Kumta, In vitro and in vivo corrosion, cytocompatibility and mechanical properties of biodegradable Mg-Y-Ca-Zr alloys as implant materials, Acta Biomater., 9 (2013) 8518-8533.

[35] UNISENSE, Hydrogen sensor user manual, 2014.

[36] T. Seo, R. Kurokawa, B. Sato, A convenient method for determining the concentration of hydrogen in water: use of methylene blue with colloidal platinum, Med. Gas Res., 2 (2012) doi:10.1186/2045-9912-1182-1181.

[37] A. Doepke, J. Kuhlmann, X.F. Guo, R.T. Voorhees, W.R. Heineman, A system for characterizing $\mathrm{Mg}$ corrosion in aqueous solutions using electrochemical sensors and impedance spectroscopy, Acta Biomater., 9 (2013) 9211-9219.

[38] X. Hu, Y. Qian, Z. Song, J. Huang, R. Cao, J. Xiao, Comparative study on $\mathrm{MoO}_{3}$ and $\mathrm{H}_{\mathrm{x}} \mathrm{MoO}_{3}$ nanobelts: structure and electric transport, Chem. Mater., 20 (2008) 1527-1533.

[39] D.A. Scherlis, Y.J. Lee, C. Rovira, S. Adams, R.M. Nieminen, P. Ordejon, E. Canadell, Concerning the origin of superstructures in hydrogen molybdenum bronzes $\mathrm{H}_{x} \mathrm{MoO}_{3}$, Solid State Ionics, 168 (2004) 291-298.

[40] J.Z. Ou, J.L. Carnpbell, D. Yao, W. Wlodarski, K. Kalantar-zadeh, In Situ Raman spectroscopy of $\mathrm{H}_{2}$ gas interaction with layered $\mathrm{MoO}_{3}$, J. Phys. Chem. C., 115 (2011) 10757-10763.

[41] P. Brimblecombe, Air composition and chemistry, 2nd ed, Cambridge University Press, New York, 1996.

[42] N. Nakashima-Kamimura, T. Mori, I. Ohsawa, S. Asoh, S. Ohta, Molecular hydrogen alleviates nephrotoxicity induced by an anti-cancer drug cisplatin without compromising anti-tumor activity in mice, Cancer Chemoth. Pharm., 64 (2009) 753-761. 
[43] D. Zhao, T. Wang, W.R. Heineman, Advances in $\mathrm{H}_{2}$ sensors for bioanalytical applications, Trac-Trend Anal. Chem., 79 (2016) 269-275. 


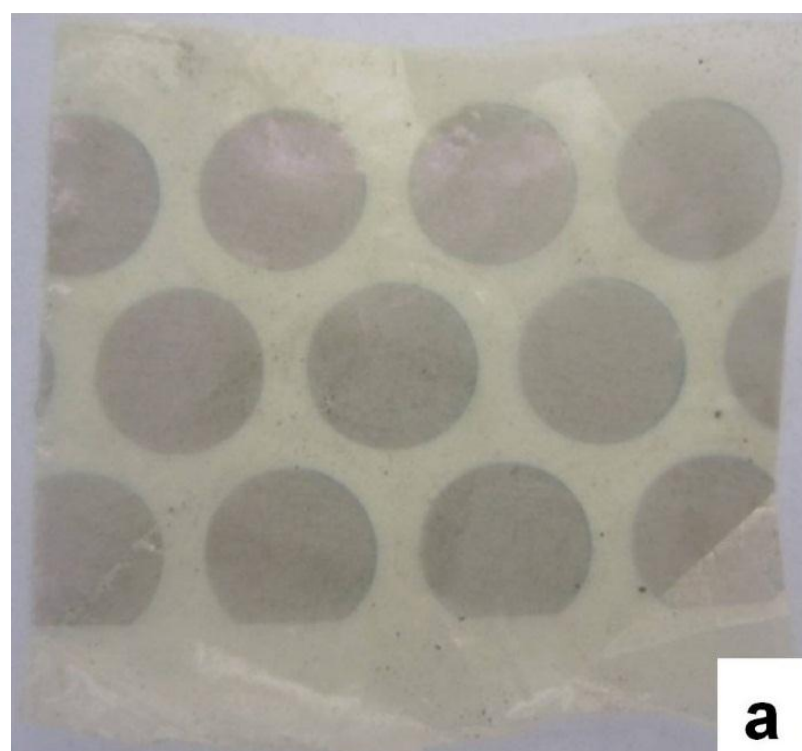




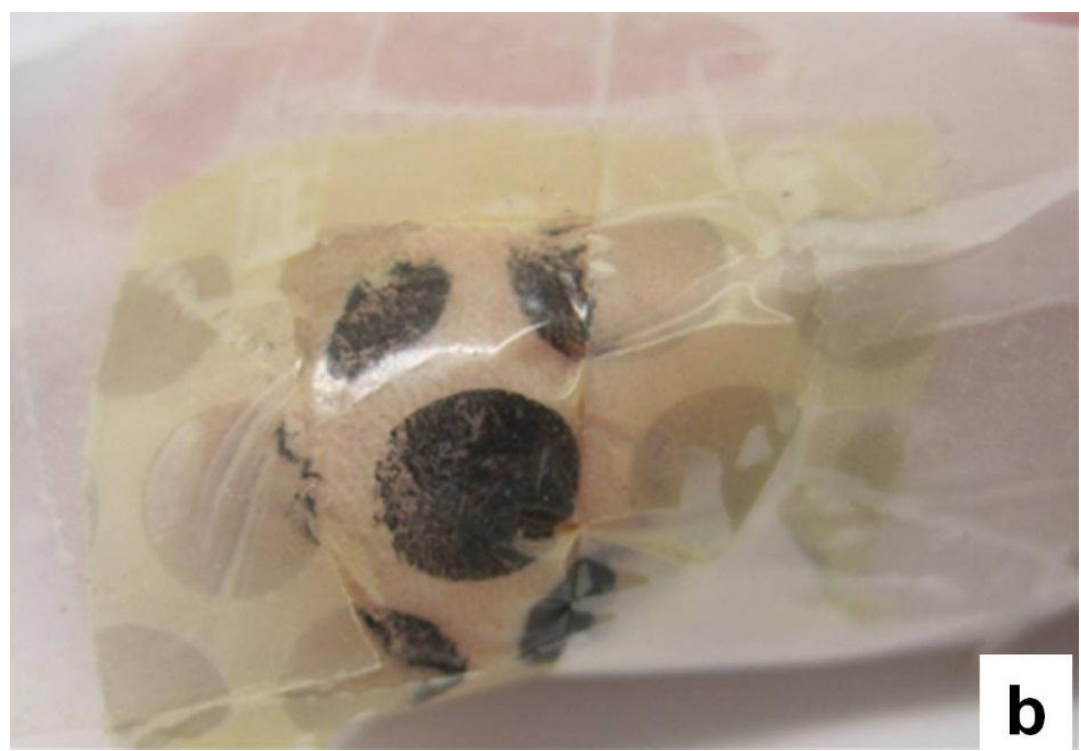




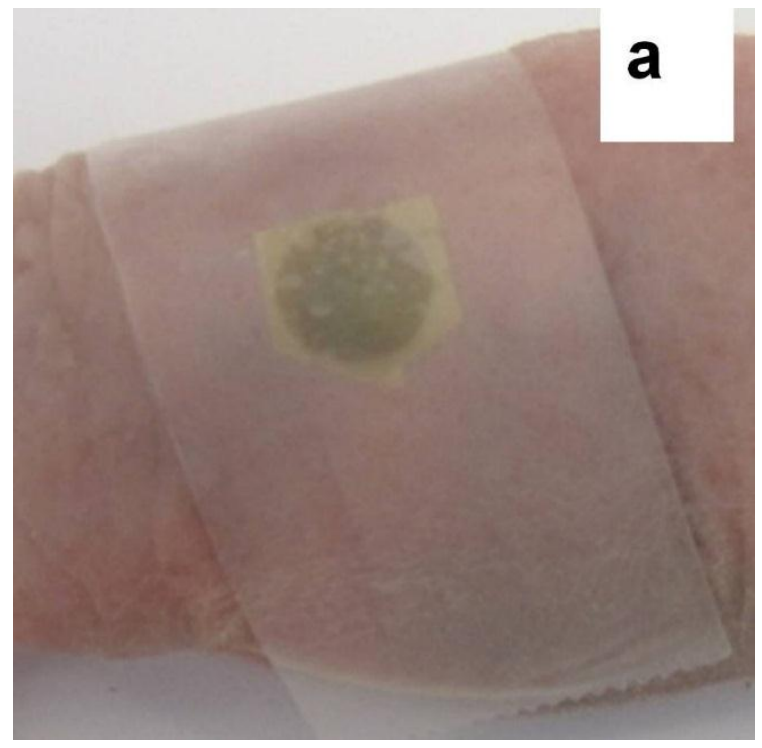




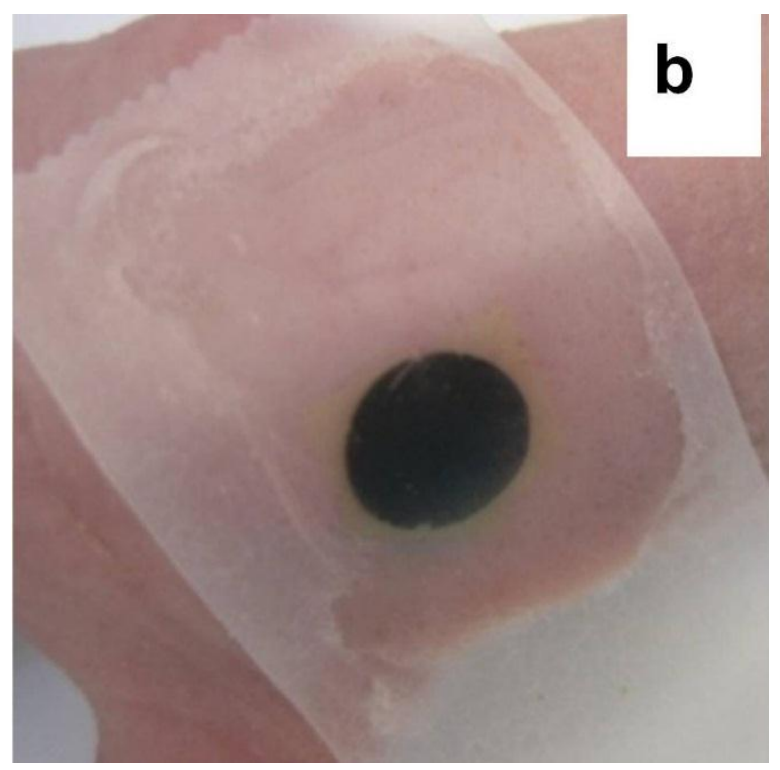


a

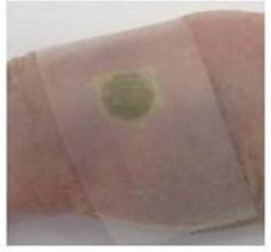

0 min

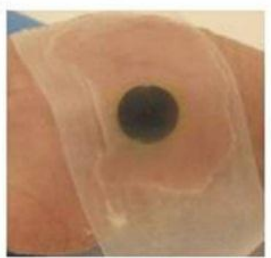

$153 \mathrm{~min}$

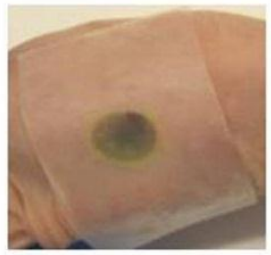

$70 \mathrm{~min}$

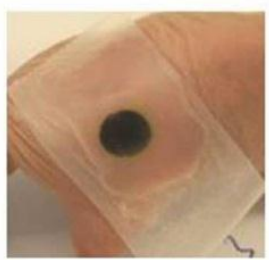

$183 \mathrm{~min}$

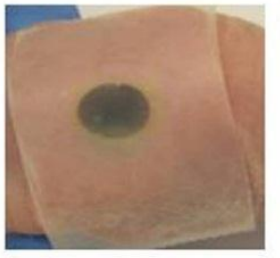

$105 \mathrm{~min}$

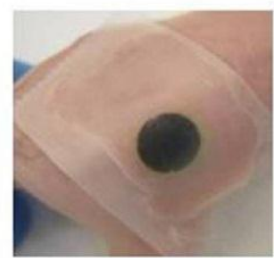

$213 \mathrm{~min}$

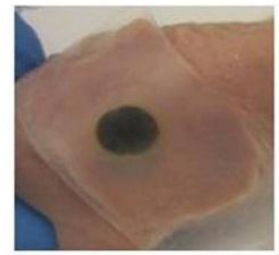

$125 \mathrm{~min}$

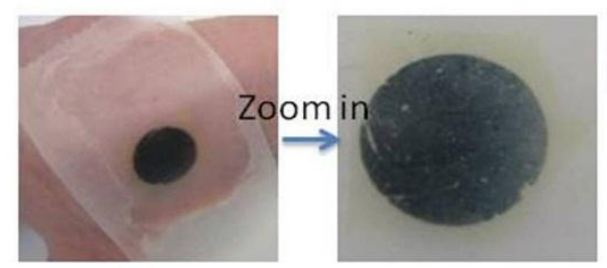

$230 \mathrm{~min}$

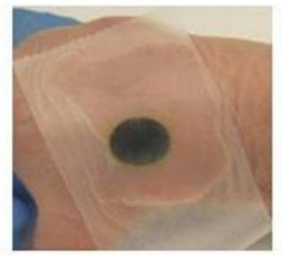

$145 \mathrm{~min}$

$230 \mathrm{~min}$ 


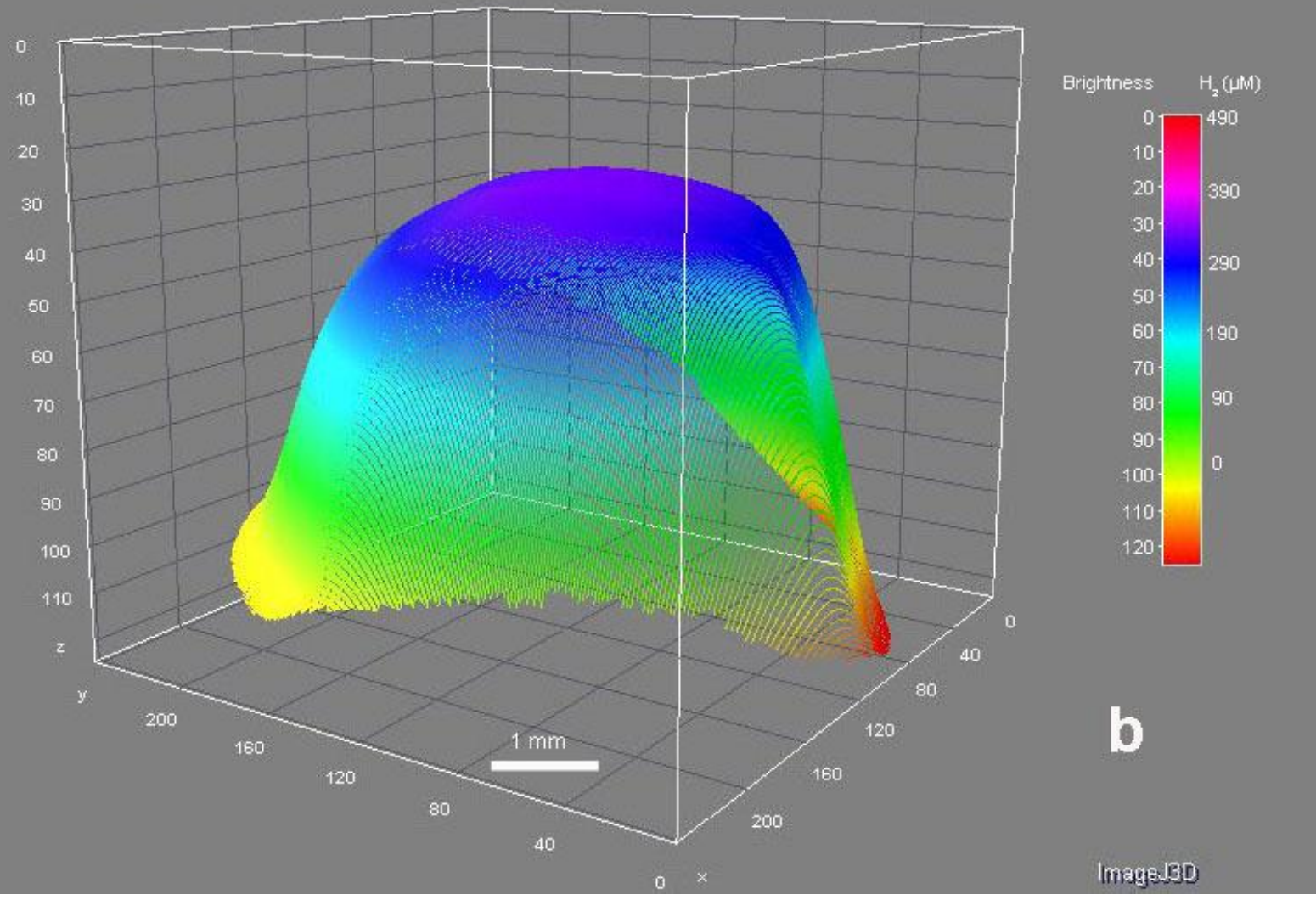




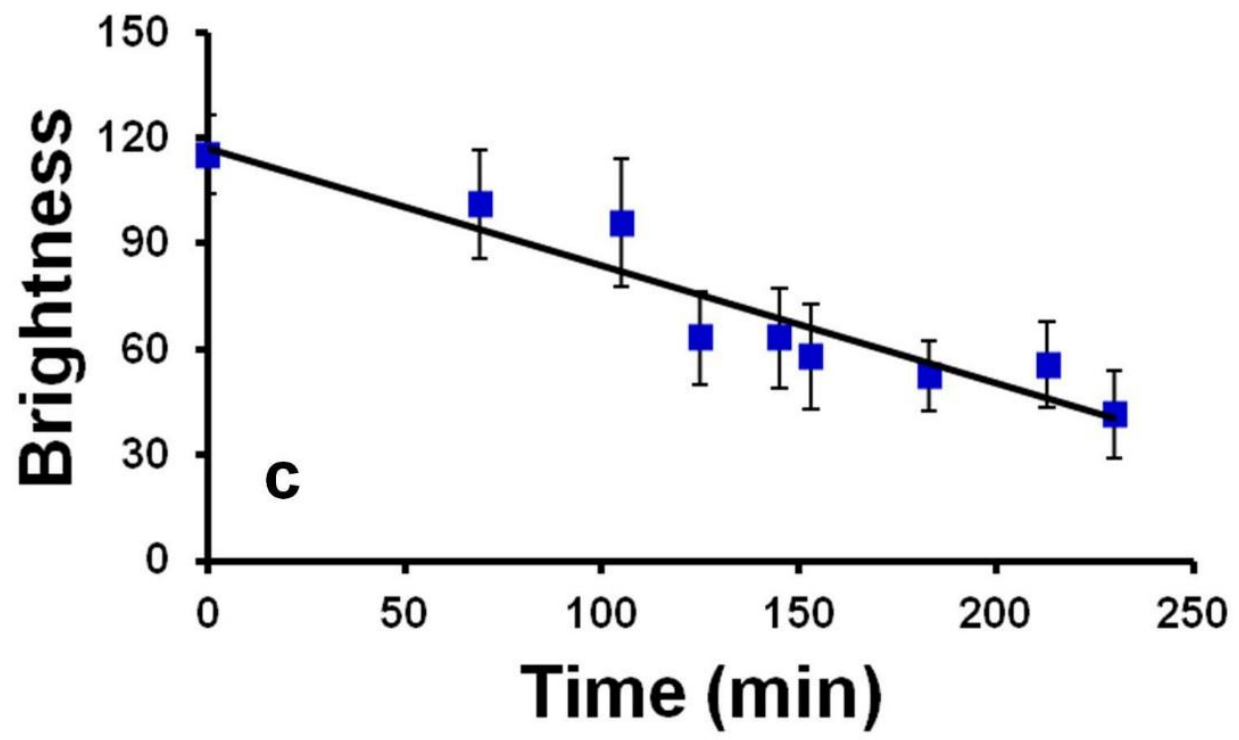


a

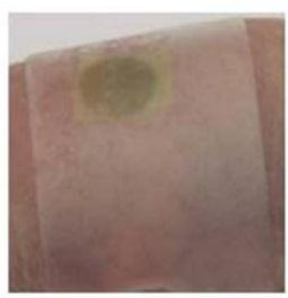

0 min

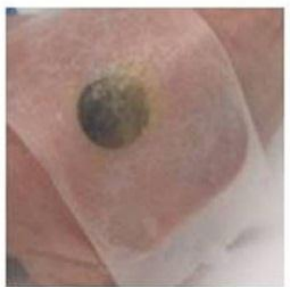

$140 \mathrm{~min}$

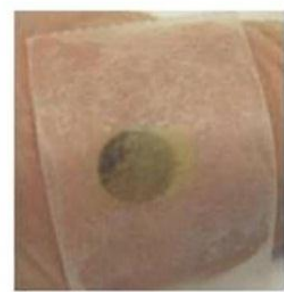

$90 \mathrm{~min}$

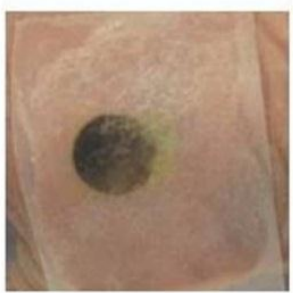

$165 \mathrm{~min}$

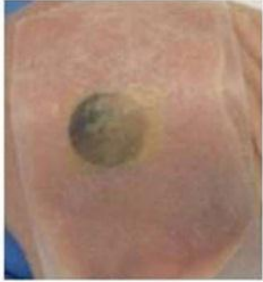

$110 \mathrm{~min}$

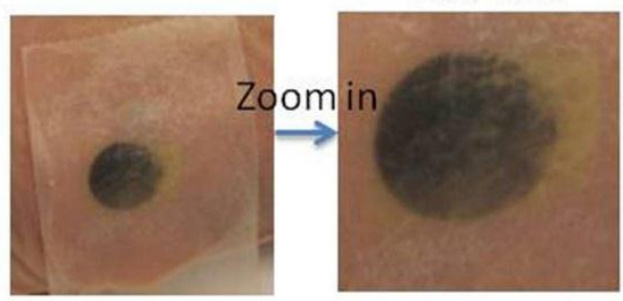

$230 \mathrm{~min}$

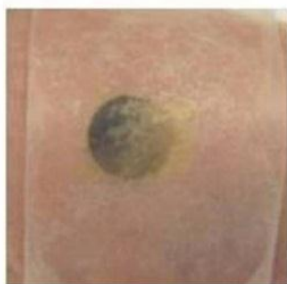

$120 \mathrm{~min}$ 


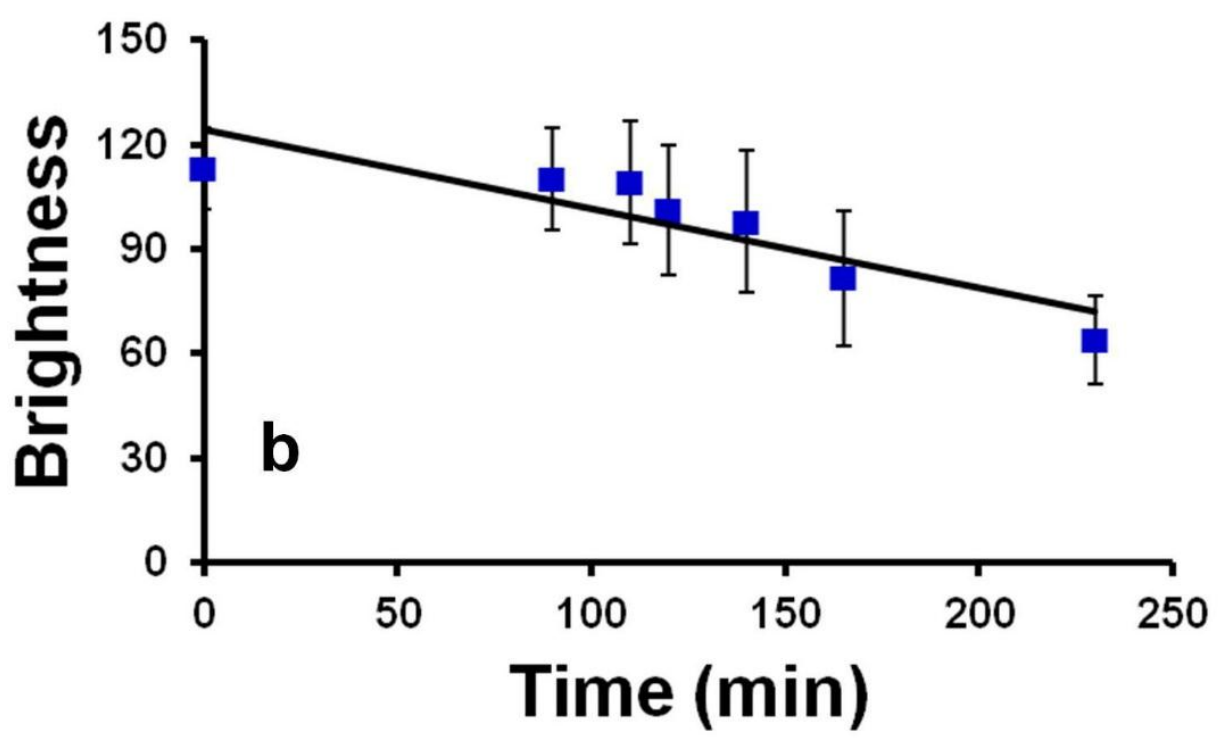




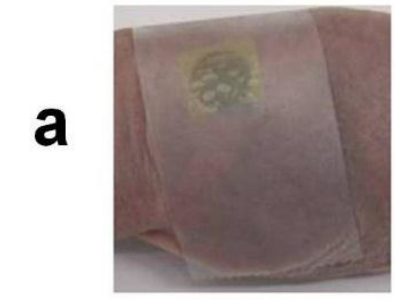

0 min

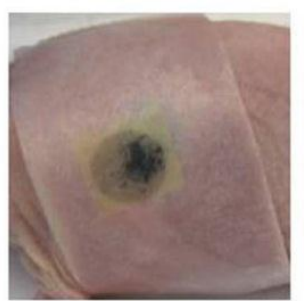

$281 \mathrm{~min}$

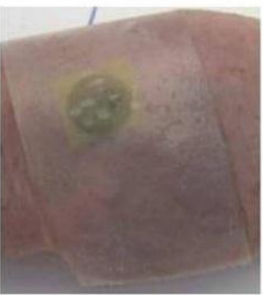

$144 \mathrm{~min}$

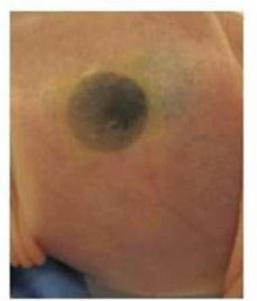

306 min

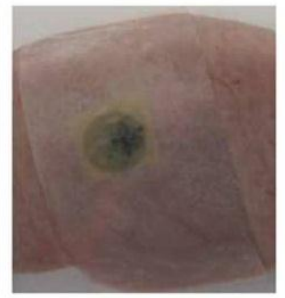

$230 \mathrm{~min}$

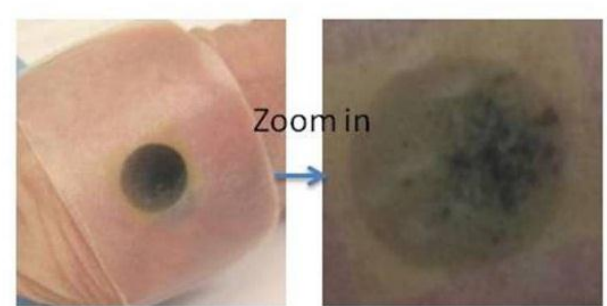

335 min

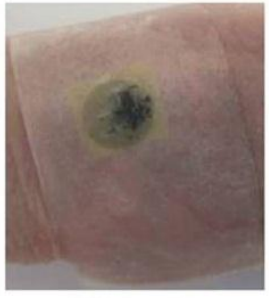

$254 \mathrm{~min}$ 


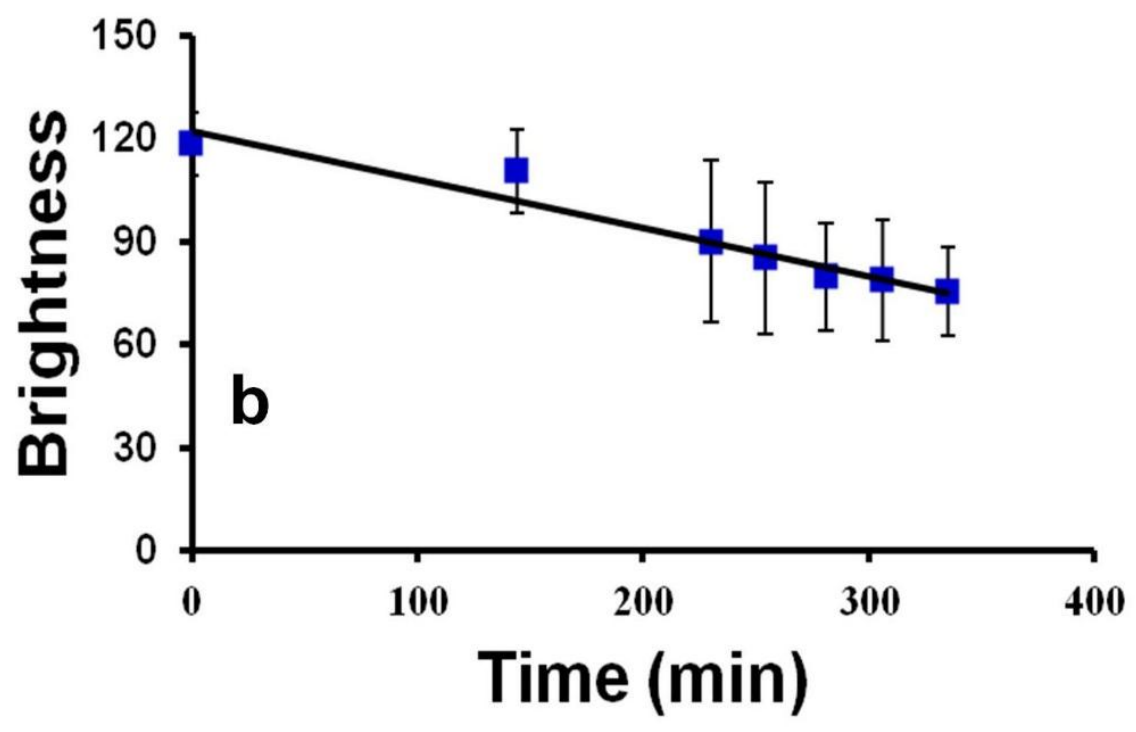




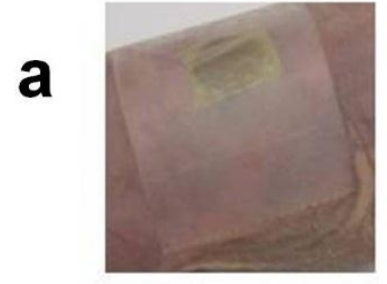

$0 \mathrm{~min}$

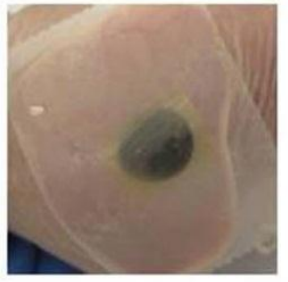

$300 \mathrm{~min}$

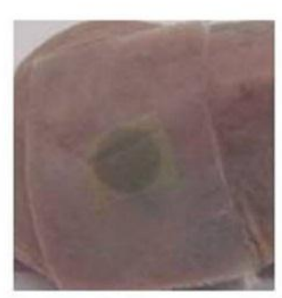

$95 \mathrm{~min}$

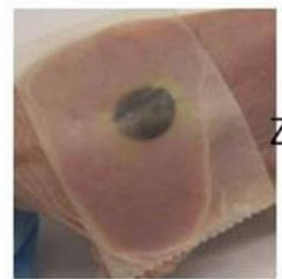

$360 \mathrm{~min}$

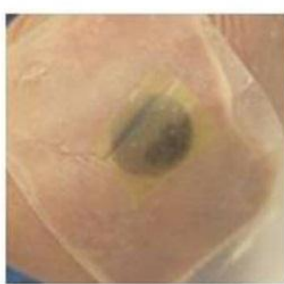

$185 \mathrm{~min}$

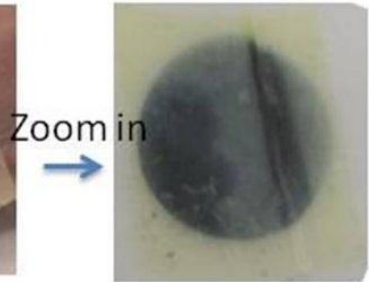

$360 \mathrm{~min}$

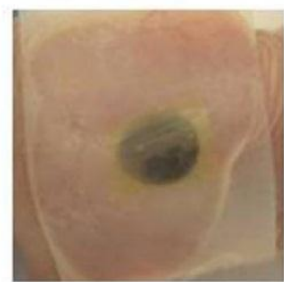

$240 \mathrm{~min}$ 


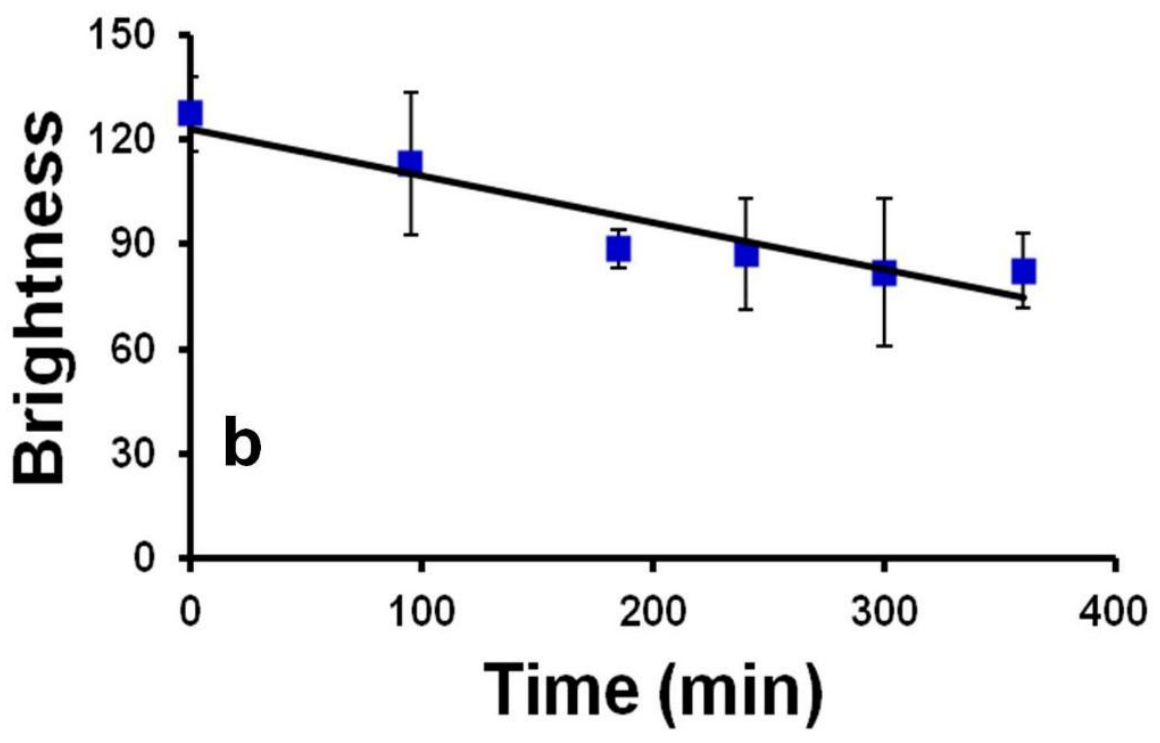


a

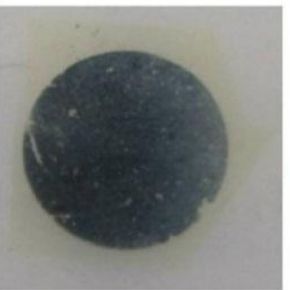

LAZ631

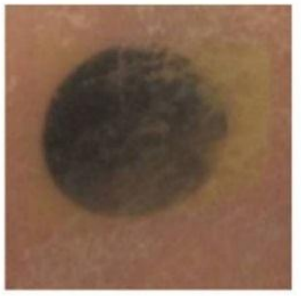

LAZ611

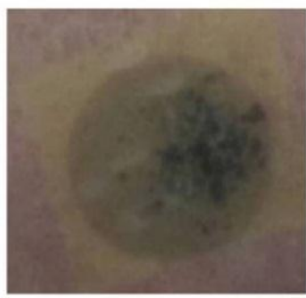

LZ61

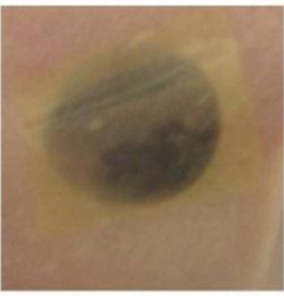

AZ31

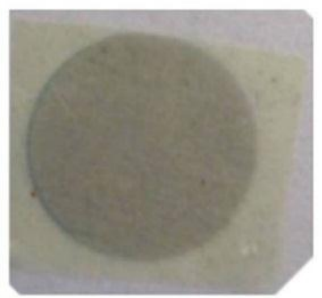

Initial Color 


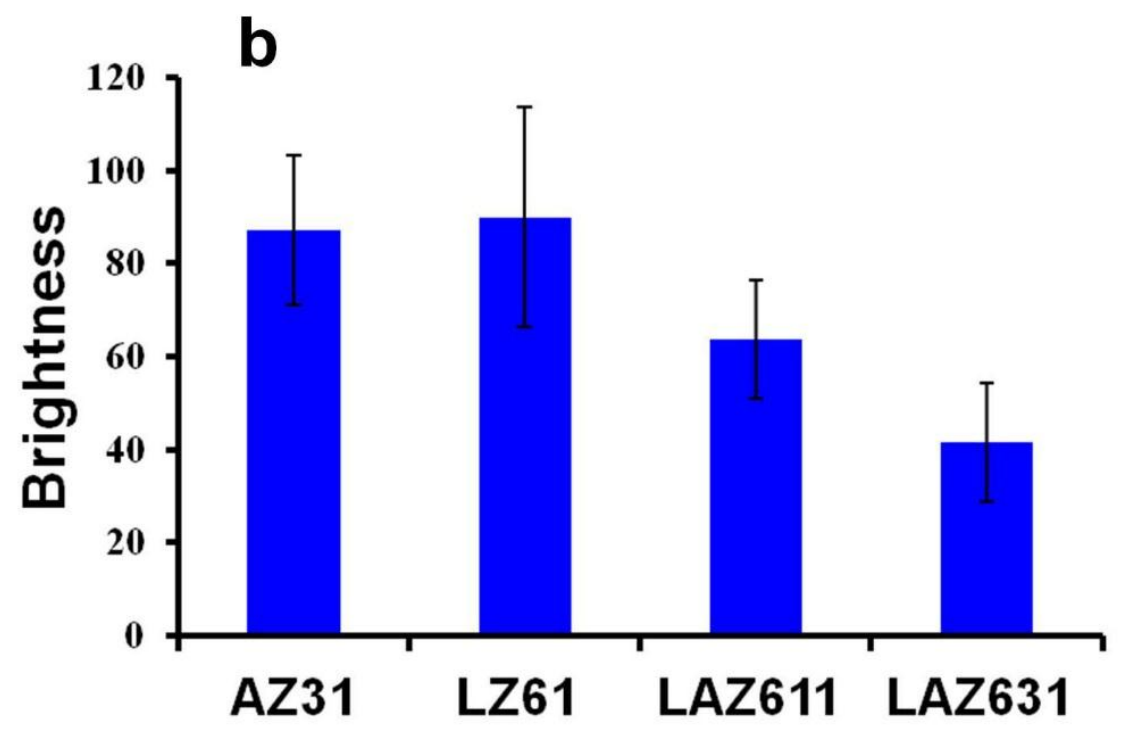




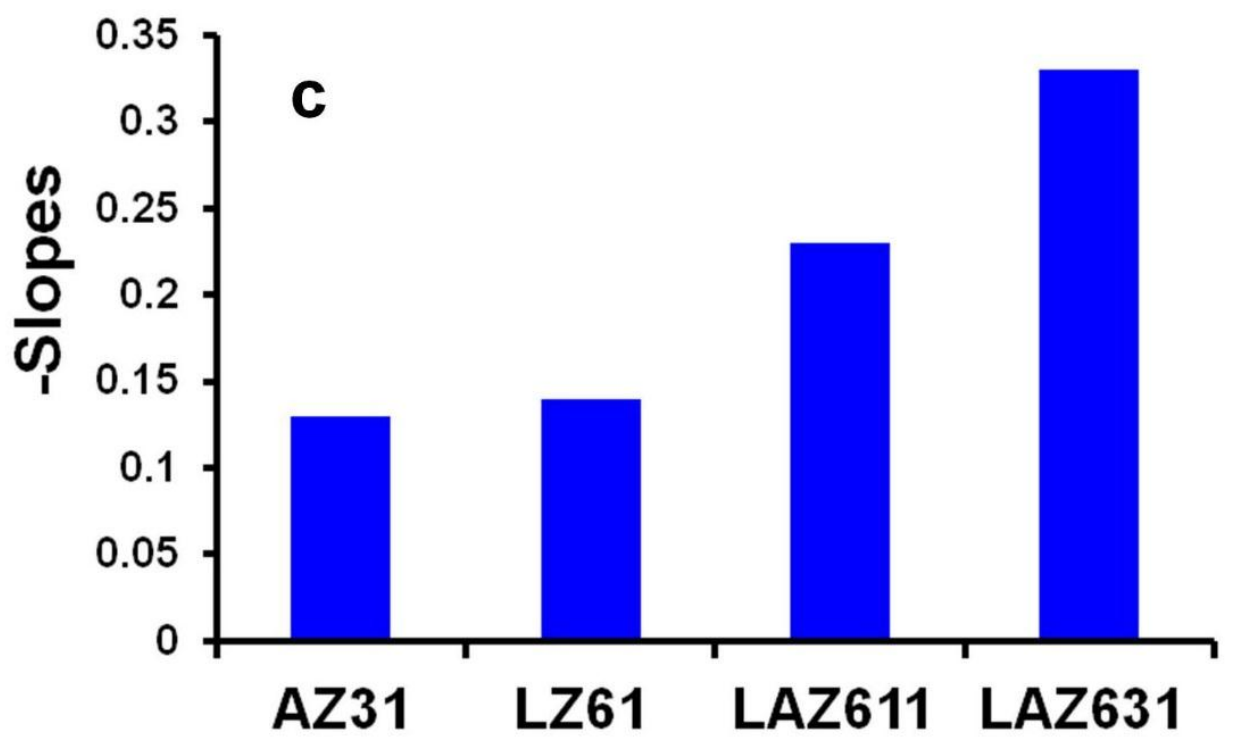




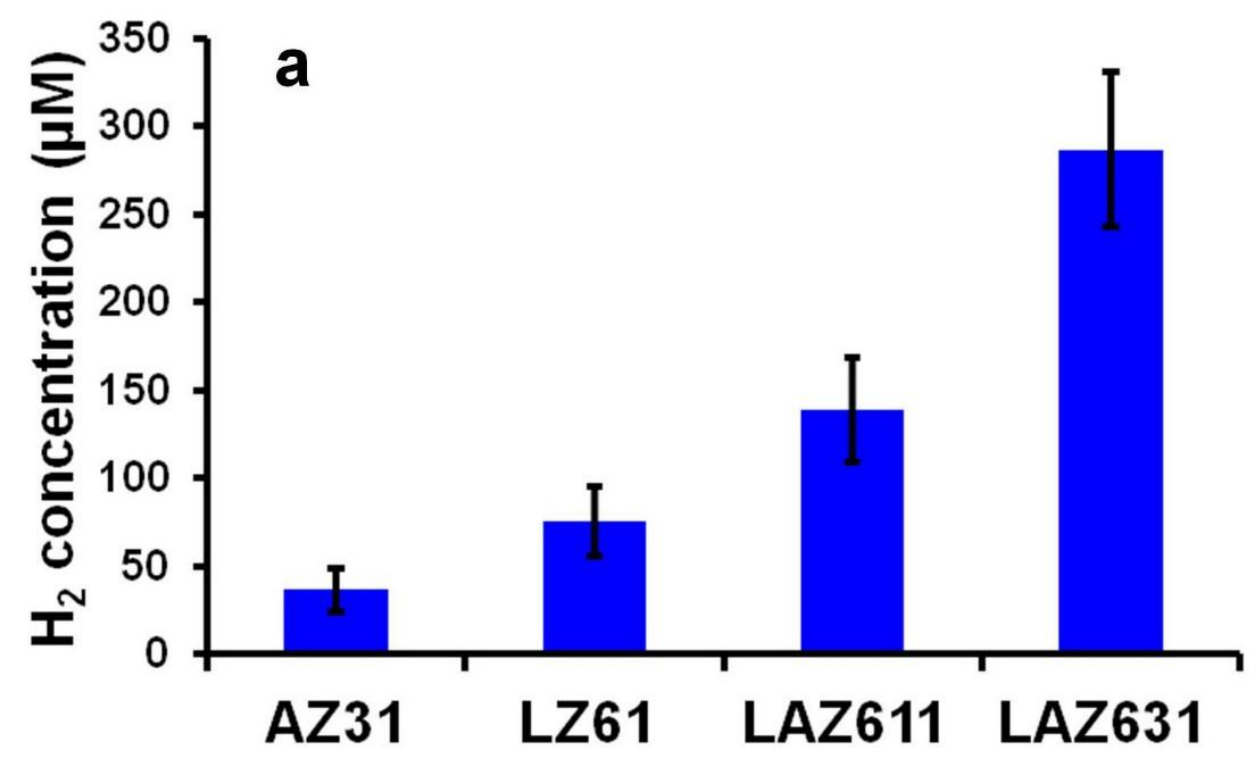




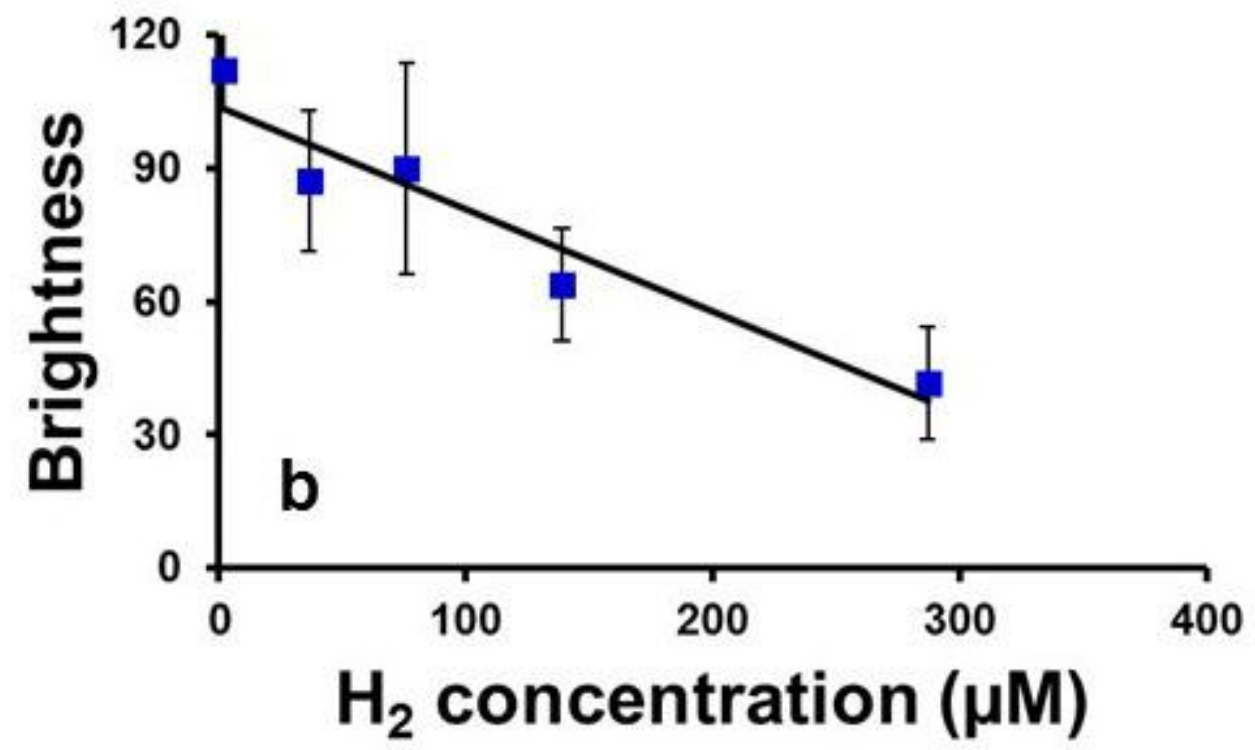


Fig. 1. Response of the thin film visual $\mathrm{H}_{2}$ sensor from Element One to $\mathrm{H}_{2}$ permeating through the skin adjacent to a Mg alloy ZK40 implant in an anesthetized laboratory mouse. (a) A piece of thin-film $\mathrm{H}_{2}$ sensor before exposure to $\mathrm{H}_{2}$ and (b) after 160 min exposure to $\mathrm{H}_{2}$ permeating through the mouse skin from the biodegrading ZK40.

Fig. 2. Color development of thin film visual $\mathrm{H}_{2}$ sensor from the $\mathrm{H}_{2}$ gas permeating through the skin above a LAZ631 implant in an anesthetized mouse at (a) 0 and (b) 213 min.

Fig. 3. (a) Thin film visual $\mathrm{H}_{2}$ sensor color development responding to $\mathrm{H}_{2}$ permeating through mouse skin adjacent to LAZ631 implant at 0, 70, 105, 125, 145,153, 183, 213 and $230 \mathrm{~min}$, (b) 3D figure of the brightness change in the $\mathrm{H}_{2}$ sensor area at $213 \mathrm{~min}$. The $z$ axis displays the $\mathrm{H}_{2}$ concentration in $\mu \mathrm{M}$ calibrated with electrochemical sensor and brightness in the region being sampled in terms of the adjacent vertical color scale. $x$ and $y$ axis represent the dimension of the $\mathrm{H}_{2}$ visual sensor in $\mathrm{mm}$. (c) calibration curve of color brightness with the exposure time.

Fig. 4. (a) Thin film $\mathrm{H}_{2}$ visual sensor color development responding to $\mathrm{H}_{2}$ passing through mouse skin adjacent to LAZ611 implant at 0, 90, 110, 120, 140, 165 and 230 min (b) calibration curve of color brightness changes with exposure time.

Fig. 5. Thin film $\mathrm{H}_{2}$ visual sensor color development responding to $\mathrm{H}_{2}$ passing through mouse skin adjacent to LZ61 implant at 0, 144, 230, 254, 281, 306 and $335 \mathrm{~min}$ and (b) calibration curve of color brightness changes with exposure time. 
Fig. 6. (a) Thin film $\mathrm{H}_{2}$ visual sensor color development responding to $\mathrm{H}_{2}$ passing through mouse skin adjacent to AZ31 implant at $0,95,185,240,300$ and 360 min and (b) calibration curve of color brightness changes with exposure time.

Fig. 7. (a) Color response of $\mathrm{H}_{2}$ visual sensor to the $\mathrm{H}_{2}$ permeating through the skin for LAZ631 (230 min), LAZ611 (230 min), LZ61 (230 min), and AZ31 (240 min) implants in anesthetized mice and initial color of visual sensor. (b) Corresponding brightness comparison. (c) Slopes of response calibration curve for each alloy.

Fig. 8. (a) $\mathrm{H}_{2}$ concentrations for different alloys measured with calibrated electrochemical (amperometric) $\mathrm{H}_{2}$ sensor. (b) Correlation of brightness from the visual sensor after exposure for 230 min and $\mathrm{H}_{2}$ concentration measured electrochemically for the four alloys. 


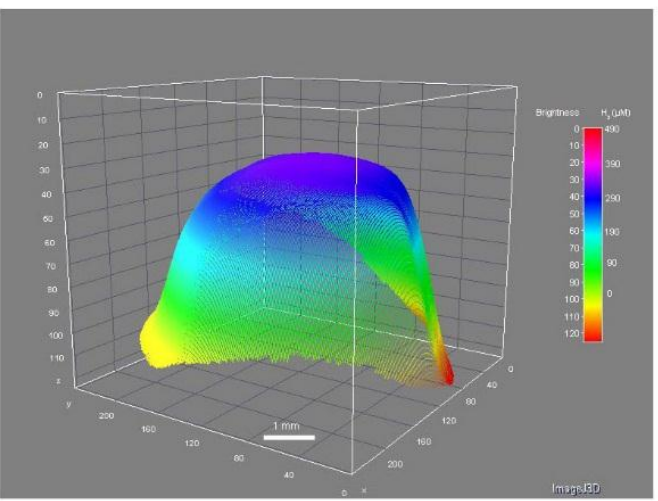

Biodegradation 